\title{
Infrastructure Shortage: A Gap Approach
}

\author{
J.M. Albala-Bertrand \\ Department of Economics \\ Queen Mary and Westfield College \\ University of London
}

\begin{abstract}
We propose a method to estimate both whether there is an overall infrastructure shortage and the optimal share of infrastructure in gross fixed capital formation (GFCF). This is based on a two-gap model and linear programming, and is illustrated with the case of Mexico (1950-1985). The results show that Mexico appears to have started with an appropriate share of core infrastructures in GFCF. Then, there would have been an infrastructure shortage up until 1964, and an infrastructure surplus thereafter. It also shows that the optimal coefficient of infrastructure investment-to-optimal output would have been around 4.5 per cent, and that each unit of infrastructure would have optimally supported over three units of GFCF. A macroeconomic shortage does not however mean that there would be a shortage everywhere, but it does imply that the economy as a whole would be in a net state of shortage. So our method may at least provide an appropriate context within which more focused analysis may be attempted.
\end{abstract}

JEL Classification: E12, 011, 041, O54, C61

Key Words: Infrastructure Shortage, Two-Gap model, Linear Programming, Mexico.

Contact Address: Dr. J.M. Albala-Bertrand, Lecturer in Development Economics, Department of Economics, Queen Mary and Westfield College, Univ. of London, Mile End Road, London E1 4NS, UK; E-Mail: J.M.Albala-Bertrand@qmw.ac.uk, Tel: 0181975 5094, Fax: 01819833580. 


\section{Introduction}

There is enough evidence that infrastructures are a fundamental contributor to growth and development. However, the issue as to whether an economy undergoes a shortage or a surplus of infrastructures is not so forthcoming. Neither is the issue as to what would be the optimal share of infrastructure in gross fixed capital formation. We propose here an alternative method, based on a two-gap model and linear programming estimations, illustrated with the case of Mexico between 1950 and 1985.

We first introduce the subject via both the importance of infrastructure and the standard assessment of shortages (section 1). Then we introduce the standard two-gap approach (section 2.1), and explain the modifications required for our purpose and present the model structure (section 2.2 ). Next, we explain the estimation procedure and the aggregate variables used (section 3). Then the results from the application to Mexico are analysed for two outlooks: the two-gap approach against time (section 4.1) and against the infrastructure coefficient (section 4.2). And finally a short conclusion follows.

\section{Infrastructure, Growth and Shortages}

Infrastructures play a crucial role in growth and development. Since the 1950s, several academic researchers have indicated that infrastructures, like transport and service networks, and education and health facilities, may represent a pre-condition for growth, as a facilitating type of capital stock for the enhancements of directly 
productive physical and human capitals (e.g. Chenery, 1953; Nurkse, 1954; and especially Hirschman, 1958). Infrastructures or public capital is seen as a complement to directly productive or private capital, normally taking the former as the necessary basis for the latter, i.e. without appropriate infrastructures there are little possibilities of deploying and occupying efficiently productive capacity. Here, infrastructure investment may act not only as a direct complement but also as an inducement for directly productive investment. This came later to represent the crowding-in theses of economic literature, i.e. public investment crowds in, rather than out, private investment, ceteris paribus (Blejer and Khan, 1984; Ortiz and Noriega, 1988; Aschauer, 1988; Barro, 1989; Bacha, 1990; Taylor, 1991). And associated with this, when taking a multisectoral view, it is also conceivable that manufacturing growth may be impaired by a suddenly increased requirement from another sector that competes in the use of the same fix infrastructure capital, in the short and medium term, i.e. by creating a shortage of infrastructures at the expense of manufacturing (Taylor, 1983).

In turn, authors like Aschauer (1989), Aaron (1990), Wickerman (1991), Munnell (1992), and many others, take public infrastructures as an input, whose services enhance the productivity of both physical and human capital. That is, the productive built environment is singled out as another fundamental input in a production function. In addition, the geographic and demographic coverage and quality of service networks, and health and education facilities, have always been considered as a foundation of socio-economic development and as a precondition of economic growth. Indeed, these are normally presented as indicators of development by international agencies and development studies (ECLA; Todaro, 1997). Accordingly, 
most governments consider repairs and new investments in infrastructures as a strategic foundation for sustained growth and development (World Bank, 1994; World Bank, 1997).

Empirical studies carried for a number of developed countries by many authors, and especially for Japan by Naoki Ono (1987), Ohkawa and Kohama (1989) and Domoto (1992) appear to confirm both the importance of infrastructure capital in economic growth and the potential growth penalties from its shortage. The former by comparing Japan with India allows for some useful generalisation about infrastructures and growth in the process of development. Gramlich (1994) in turn concentrates on the issue of infrastructure shortage and its evidence in the US, and surveys the literature on the issue. While criticising some of the available approaches, this study also lends support to the importance of infrastructure in economic growth and development. However, the issue as to whether an economy undergoes a shortage or a surplus of infrastructures is not so clear-cut and forthcoming.

Some authors have attempted to determine empirically whether there is an infrastructure insufficiency or surplus, by using either non-economic techniques or theory-driven economic methods (Ibid.). Examples of the former are localised engineering measures of infrastructure requirement and local voting preferences as regards public works (FHA, 1989; Peterson, 1991). These are useful, but largely devoid of institutional or economic meaning. As regards economic methods, the two predominant ones are either cost-benefit analysis or econometric studies (Aschauer, 1989; Gramlich, 1990; Munnel 1990; Feltenstein and Ha, 1995). The former allows focusing on the internal rate of return of specific infrastructures, which may indirectly 
be interpreted as an indication of shortage (if this rate is larger than that for the economy). But here the inter-geographic, inter-sectoral or general equilibrium repercussions from localised infrastructures are difficult to assess, which may make the exercise less sound than required. Econometric studies in turn rely theoretically upon either well-behaved production function or cost functions (Berndt and Hansson, 1992; Aschauer, 1993; Evans and Karras, 1993). In addition, econometrics may not be an appropriate technique to establish potential values from empirical data, as it has no optimising mechanism. Therefore, the results are normally validated by theory rather than empirical analysis, which may make them tightly associated with too-strong working assumptions, like those of perfect competition.

Given the above considerations, in this paper, we propose a macro-level exercise to assess infrastructure shortage (surplus), based theoretically on two-gap models and empirically on linear programming methods, using as an illustration the case of Mexico.

\section{Two-Gap Analysis}

\subsection{Precedents}

As an extension of the Harrod-Domar model to the open economy (Thirwall, 1994), in the context of macroeconomic accounting, and under the assumption of complementarity, or at least weak substitutability, between foreign and domestic savings, the two-gap model was devised as an ex-ante analytical framework to assess

foreign exchange requirements (Chenery and Bruno, 1962; McKinnon 1964; Chenery 
and Strout, 1966). It attempted to answer whether a country was likely to undergo a potential shortage of foreign savings or exchange, relative to domestic savings ("trade or foreign exchange gap"), or a potential shortage of domestic savings, relative to foreign savings ("saving gap"). In the case of the former, with the help of estimated trends in domestic savings, trade and investment productivity, the foreign aid requirement (to complement domestic savings), so as to satisfy a given GDP growth rate could then be determined. If this aid (or foreign savings) was unattainable then the growth rate had to be revised down, at least in the short and medium term. Meanwhile, some policy-induced structural changes can be attempted so as to generate or attract more foreign exchange inflows in the future.

From aggregate demand accounting, it can be shown that in equilibrium or ex-post, if there is a difference between investment and domestic savings, there has to be the same difference between imports and exports, representing foreign savings, ceteris paribus. But this may not be true ex-ante, as savers, investors, exporters and importers are normally different agents with fairly independent behaviours. Therefore, for a given level of potential output or growth, the required foreign savings to close the saving-investment gap may not necessarily be of the same size as that required to close the trade gap, ex-ante. Which means that the two differences or gaps may not be equal. Or alternatively, a given amount of foreign savings may produce two different ex-ante valuations for potential output or growth. One of them for the savinginvestment balance and the other for the trade balance. As the two growth valuations cannot be reached at the same time, then only the smaller of the two can be satisfied ex-ante, with repercussions for resource usage, i.e. the smaller of the two binds or constrains potential output down. If the smaller of the two is the growth valuation 
from the trade balance, we say that the economy is "foreign exchange constrained", meaning that it experiences foreign exchange shortage. Conversely, we say that the economy is "savings constrained" if domestic resources are not large enough to absorb or use productively the available foreign exchange ${ }^{(1)}$. This thought process will become clearer as we present our actual model below.

The conceptual framework of the model has however been rarely used outside the above foreign exchange context, which is surprising, as it could address a number of other issues with advantage. Actually, any time there are at least two complementary factors contributing to given levels of production or growth (or any other given outcome, for that matter), the model can be used to assess potential mismatches between the two factors, i.e. shortages or surpluses. We call the mismatch a gap rather than a disequilibrium, as we assume that this inconsistency cannot be eradicated in the short and medium term by resorting to the "right prices", or indeed to legislation. This means that the gap is associated to institutional structure, rather than to market disequilibria alone ${ }^{(2)}$.

\subsection{A Gap Model to Assess the Infrastructure Gap.}

(a) Assumptions and Outlook

In our usage, there are however a few outlook changes from the classic two- or threegap models. First, as we want to assess whether there has been a surplus or shortage of infrastructure in the recent past, the analysis has to be based on actual rather than

potential investment, so we change focus from the generation of savings to actual 
investment. Therefore, on this count the model becomes and ex-post, rather than exante, accounting and analytical framework. But as we still want to assess the potential output or growth that was theoretically achievable from actual capital or investment, we can trace back an ex-ante element, which may have been affected by the composition of total capital or investment. Second, we do not focus on foreign exchange but on "core infrastructure", or herefrom infrastructure capital or infrastructure investment, defined as all types of road networks (including bridges, tunnels, terminals and the like), utility networks (including communications, electricity, water, gas, oil, sewerage and the like), power generating infrastructures, and the like. Third, given this, contrary to the standard two-gap analysis, our model focuses on the supply, rather than on the demand, side of the economy ${ }^{(3)}$.

Let us assume that both infrastructure capital and directly productive capital (herefrom, productive capital) are mutually complementary to each other for production, i.e. one type cannot be employed in the absence of the other type. The complementary assumption, or at least weak substitutability, is well supported in the literature, especially between "core infrastructure" capital and directly productive capital (Munnel 1990; Domoto 1992, Felstein and Ha 1995; Mamatzakis, 1997). Let us also assume that any other requirement for production is constant, fully available or passive, i.e. they accommodate to satisfy any targeted requirement. Then, the problem can be reduced to find the maximum output derived from the actual availability of one type of capital, assuming that the other is fully available. That is, (i) maximum output from available infrastructure capital $\left(\mathrm{K}_{\mathrm{f}}\right)$, assuming that productive capital $\left(\mathrm{K}_{\mathrm{p}}\right)$ is not a constraint or is fully available; and (ii) maximum output from available productive 
capital $\left(\mathrm{K}_{\mathrm{p}}\right)$, assuming that infrastructure capital $\left(\mathrm{K}_{\mathrm{f}}\right)$ is not a constraint or is fully available.

Given that data on capital stock is not readily available, and given that it is sometimes more useful to work with growth rates and ratios than absolute numbers, the above can be transformed into ratios derived from incremental changes, by assuming that the two capitals are in perfect balance at a given base year. Therefore, the problem consists in finding (i) the maximum growth from the available infrastructure investment coefficient $\left(\mathrm{I}_{\mathrm{f}} / \mathrm{Y}\right)$, assuming that the directly productive investment coefficient $\left(\mathrm{I}_{\mathrm{p}} / \mathrm{Y}\right)$ is not a constraint; and (ii) the maximum growth from the available productive investment coefficient $\left(\mathrm{I}_{\mathrm{p}} / \mathrm{Y}\right)$, assuming that the infrastructure investment coefficient $\left(\mathrm{I}_{\mathrm{f}} / \mathrm{Y}\right)$ is not a constraint.

If the two types of investment were in equilibrium for production, i.e. matching their mutually required complements for full-capital employment production, then there would be no gap between the two, or the two would be mutually binding each other. A gap arises only if their mutual requirements do not match, i.e. there is more of one type of investment than the other type can support or use. That is, there could be either potentially more productive investment than the available infrastructure investment can support (i.e. infrastructure shortage), or there could be potentially more infrastructure investment than the available productive investment can use (i.e. infrastructure surplus). Therefore, production or growth cannot exceed the levels that the lower of the two investments can support or use. That is, whatever the excessive level of productive investment, potential production or growth cannot exceed the levels allowed by infrastructure investment, and vice versa. This means that for a gap 
to exist, there should be excess investment of one the two types, this excess remaining idle in production, as it cannot be supported or used by the other type of investment.

Given that actual growth is the outcome of both types of investment (and all other factors) operating in complementary terms, from actual aggregate data we cannot directly find either the potential growth rate from productive investment $\mathrm{g}_{\mathrm{p}}$ or the potential growth rate from infrastructure investment $\mathrm{g}_{\mathrm{f}}$. Therefore, we have to establish the following: (i) the optimally required ratio or relation between the two investment types for balanced growth, i.e. without excess investment; and (ii) the maximum or optimal output or growth from one type of investment, given the other, assuming that the ratio or relation between the two is stable over time and scale.

\section{(b) The Model Structure}

For simplicity, let us assume a fixed-coefficient production function, but any type of function can be accommodated, if useful. Let us also assume that capital or investment is the only limiting factor, which does not need to be true, but does not change the thrust of the model.

$\mathrm{Y}=\operatorname{Min}\left[\mathrm{K}_{\mathrm{p}} / \mathrm{k}_{\mathrm{p}}, \mathrm{K}_{\mathrm{f}} / \mathrm{k}_{\mathrm{f}}\right] \quad$ (Production Function)

Where $\mathrm{K}_{\mathrm{i}}\left(\mathrm{i}: \mathrm{p}\right.$ or $\mathrm{f}$ ) are two types of complementary capital, $\mathrm{k}_{\mathrm{i}}$ represents the optimal or potential capital-output ratio, p: productive capital or investment and f: infrastructure capital or investment. Notice that this formulation allows either type of capital to remain idle, as either capital can only operate productively in complement 
with the other, i.e. once one type is fully used, if there is any remnant of the other, this cannot be activated, and therefore remains idle.

In equilibrium, without idle capacity, the following should hold:

$\mathrm{Y}=\mathrm{K}_{\mathrm{p}} / \mathrm{k}_{\mathrm{p}}=\mathrm{K}_{\mathrm{f}} / \mathrm{k}_{\mathrm{f}} \quad$ (In equilibrium)

Notice that (2) implies that $\mathrm{K}_{\mathrm{p}} / \mathrm{K}_{\mathrm{f}}=\mathrm{k}_{\mathrm{p}} / \mathrm{k}_{\mathrm{f}}$, i.e. in equilibrium the relation between capitals is the same as that between capital-output ratios or average productivities, which means that if we find empirically the value of this ratio for capital (or investment), we also should be able to find their average productivity ratio. Total capital is:

$\mathrm{K}=\mathrm{K}_{\mathrm{p}}+\mathrm{K}_{\mathrm{f}}=\mathrm{k}_{\mathrm{p}} \mathrm{Y}+\mathrm{k}_{\mathrm{f}} \mathrm{Y}=\left(\mathrm{k}_{\mathrm{p}}+\mathrm{k}_{\mathrm{f}}\right) \mathrm{Y}=\mathrm{kY}$

Assuming that the average capital-output ratio is the same as the incremental capitaloutput ratio:

$\mathrm{k} \Delta \mathrm{Y}=\left(\mathrm{k}_{\mathrm{p}}+\mathrm{k}_{\mathrm{f}}\right) \Delta \mathrm{Y}=\Delta \mathrm{K}=\Delta \mathrm{K}_{\mathrm{p}}+\Delta \mathrm{K}_{\mathrm{f}}=\mathrm{I}_{\mathrm{p}}+\mathrm{I}_{\mathrm{f}}=\mathrm{I}$

Where $\Delta$ : variation, I: investment. From (4):

$\mathrm{k}=\Delta \mathrm{K} / \Delta \mathrm{Y}=\mathrm{I} / \Delta \mathrm{Y}$ (optimal or potential incremental capital-output ratio)

We require also knowing the following ratio: 
$\varepsilon=\mathrm{I}_{\mathrm{p}} / \mathrm{I}_{\mathrm{f}}$

Notice that $\varepsilon$ is an optimal technical/structural, not necessarily behavioural, relationship. And, given that:

$\mathrm{I}=\mathrm{I}_{\mathrm{p}}+\mathrm{I}_{\mathrm{f}}$

Then:

$\mathrm{I}=(1+\varepsilon) \mathrm{I}_{\mathrm{f}}$

Dividing (5) by $\mathrm{Y}$ and rearranging:

$\mathrm{g}_{\mathrm{s}}=(1 / \mathrm{k}) \mathrm{v}_{\mathrm{s}}$

Where $\mathrm{g}_{\mathrm{s}}=\Delta \mathrm{Y} / \mathrm{Y}$ is the optimal growth rate that comes from total investment (we use subindex "s"to refer to this), and $\mathrm{v}_{\mathrm{s}}=\mathrm{I} / \mathrm{Y}$ or $\mathrm{v}_{\mathrm{s}}=\left(\mathrm{I}_{\mathrm{p}} / \mathrm{Y}\right)+\left(\mathrm{I}_{\mathrm{f}} / \mathrm{Y}\right)=\mathrm{v}_{\mathrm{p}}+\mathrm{v}_{\mathrm{f}}$.

Therefore, replacing (8) in (9):

$\mathrm{g}_{\mathrm{f}}=[(1+\varepsilon) / \mathrm{kY}] \mathrm{I}_{\mathrm{f}}$ or $\mathrm{g}_{\mathrm{f}}=[(1+\varepsilon) / \mathrm{k}] \mathrm{v}_{\mathrm{f}}$

Where $\mathrm{g}_{\mathrm{f}}=\Delta \mathrm{Y} / \mathrm{Y}$ is the optimal growth rate that comes from infrastructure investment (we use subindex " $\mathrm{f}$ " to refer to this), and $\mathrm{v}_{\mathrm{f}}=\mathrm{I}_{\mathrm{f}} / \mathrm{Y}$. 
Once (9) and (10) have been estimated, a quantitative gap can be built as:

$\mathrm{G}=\mathrm{g}_{\mathrm{s}}-\mathrm{g}_{\mathrm{f}}=(1 / \mathrm{k}) \mathrm{v}_{\mathrm{s}}-[(1+\varepsilon) / \mathrm{k}] \mathrm{v}_{\mathrm{f}}=(1 / \mathrm{k})\left[\mathrm{v}_{\mathrm{s}}-(1+\varepsilon) \mathrm{v}_{\mathrm{f}}\right]=(1 / \mathrm{k})\left(\mathrm{v}_{\mathrm{p}}-\varepsilon \mathrm{v}_{\mathrm{f}}\right)$

Where:

$$
\begin{aligned}
& >0 \text { if } g_{s}>g_{f} \\
G & =0 \text { if } g_{s}=g_{f} \\
& <0 \text { if } g_{s}<g_{f}
\end{aligned}
$$

The gap is the result of the difference between the two growth rate valuations: one coming from total investment and another from infrastructure investment. This is an alternative and more convenient way to say the same as with the difference between productive and infrastructure investment (see last term of equation (11)). Given that total investment includes infrastructure investment, the gap arises every time the composition of total investment is inconsistent with the $\varepsilon$ ratio. In other words, the gap arises when the growth potential from infrastructure investment does not match that of total investment. Only the smaller of the two growth rates is attainable.

The gap $\mathrm{G}$ is equal to 0 , when $\mathrm{v}_{\mathrm{p}}$ is equal to $\varepsilon \mathrm{v}_{\mathrm{f}}$. If so, we are consistently back to the investment ratio in equation (6), i.e. $\varepsilon=\mathrm{v}_{\mathrm{p}} / \mathrm{v}_{\mathrm{f}}=\mathrm{I}_{\mathrm{p}} / \mathrm{I}_{\mathrm{f}}$. This is the optimal composition or relationship between the two investment types that the economy should keep for mutually bound (or well-matched) growth. In turn, every time $\mathrm{G}$ is different from 0 , the value of $\mathrm{G}$ represents potential growth rate lost or unattained (in percentage 
points), given a binding investment. For example, if $G>0$ then the foregone growth rate is due to a binding shortage of infrastructure investment, while if $G<0$ the converse case holds.

This gap can be calculated both against years and against the optimal infrastructure investment ratio $\mathrm{v}_{\mathrm{f}}$. The former accounts for the gap type (i.e. infrastructure shortage or surplus) and its size for every year in the period considered. The latter in turn accounts for the gap type and its size with respect to the infrastructure investment ratio for the whole period. From the former we can learn in which years there was a potential shortage (surplus) of infrastructure. In turn, from the latter we can determine (i) what is the optimal relation between the two types of investment ( $\varepsilon$ ); and (ii) for which infrastructure investment ratios there was an overall shortage (surplus) of infrastructure in the period considered as a whole. The latter can also be represented in the customary two-gap graph, as will be shown later.

\section{Estimation Procedure}

Our next step is to estimate the parameters of equations (9) and (10). Let $\alpha=1 / \mathrm{k}$ and $\beta=(1+\varepsilon) / \mathrm{k}$. That is, in equilibrium $\varepsilon=(\beta / \alpha)-1$. Therefore, once the optimal $\alpha$ and $\beta$ have been estimated, at equilibrium (i.e. $g_{s}=g_{f}$ ), we can find the optimal value of the capital type ratio $\varepsilon$, or what is equivalent the optimal composition of investment for full utilisation of capital, i.e. for mutually binding constraints.

To search for optimal output from available investment (total and infrastructure, respectively), we resort to a modification of the linear programming method proposed 
by Berg (1984) and applied by Marfan and Artiagoitia (1989) to estimate potential output. The linear programme seeks to minimise the total gap between potential and actual output, for the whole period, provided that actual output is smaller than or equal to potential output in each particular year. To this effect, we formulate output of each year as the sum of output in the previous year (minus the capacity-induced output lost to depreciation) plus the addition to output this year coming from the "productivity"(5) of gross investment in the previous year. That is:

$$
\mathrm{Y}_{\mathrm{t}}=(1-\gamma) \mathrm{Y}_{\mathrm{t}-1}+\delta_{\mathrm{t}-1} \mathrm{I}_{\mathrm{t}-1}
$$

Where $\gamma$ is the depreciation rate, the asterisk " *" indicates the optimal or potential value of the variable (here output), and " $\mathrm{t}$ " represents time. In turn, $\delta_{\mathrm{t}-1}=\mathrm{a}+(\mathrm{t}-1) \mathrm{b}$ represents the "productivity" of capital or investment. That is, this productivity is calculated as the sum of an average component and a linear marginal one. If, from the data, there is a linear marginal component, the programme will pick it. This formulation allows more flexibility than using only an average estimate, as it avoids an overestimation of potential output in the first years.

The first-difference equation derived from (13) is:

$$
\mathrm{Y}^{*}{ }_{\mathrm{t}}=(1-\gamma)^{\mathrm{t}} \mathrm{Y}^{*}{ }_{0}+\mathrm{a} \sum \mathrm{I}_{\mathrm{i}-1}(1-\gamma)^{(\mathrm{t}-\mathrm{i})}+\mathrm{b} \sum \mathrm{I}_{\mathrm{i}-1}(\mathrm{i}-1)(1-\gamma)^{(\mathrm{t}-\mathrm{i})}
$$

Where the sums $\Sigma$ move along i: $0, . ., \mathrm{t}$. And the base year $\mathrm{Y}^{*}{ }_{0}$, and the productivities $\mathrm{a}$ and $\mathrm{b}$ are the parameters to estimate. The linear programme then takes the following shape: 
Minimise: $\mathrm{Z}=\Sigma\left(\mathrm{Y}_{\mathrm{t}}-\mathrm{Y}_{\mathrm{t}}\right)$ or

$\mathrm{Z}=\mathrm{Y}_{0}{ }_{0} \Sigma(1-\gamma)^{\mathrm{t}}+\mathrm{a} \Sigma \Sigma \mathrm{I}_{\mathrm{i}-1}(1-\gamma)^{(\mathrm{t}-\mathrm{i})}+\mathrm{b} \Sigma \Sigma \mathrm{I}_{\mathrm{i}-1}(\mathrm{i}-1)(1-\gamma)^{(\mathrm{t}-\mathrm{i})}-\Sigma \mathrm{Y}_{\mathrm{t}}$

Subject to:

$\mathrm{Y}^{*}>=\mathrm{Y}_{\mathrm{t}}$

$\mathrm{Y}^{*}, \mathrm{a}, \mathrm{b}>=0$

Where the $\mathrm{Y}^{*}{ }_{\mathrm{t}} \mathrm{s}$ are calculated via equation (4), the first sum $\Sigma$ and also $\mathrm{Y}_{\mathrm{t}}$ and $\mathrm{Y}_{\mathrm{t}}$ move along t: $1, \ldots, \mathrm{n}$, and the second sum $\Sigma$ moves along i: $1, \ldots, \mathrm{t}$.

Linear programming, contrary to econometrics, does not smooth trends into average deviations, but picks the best or optimal combination of values (extreme points), while ignoring the others (Chiang, 1984; Dervis, 1882). The main drawback of the method is that the results cannot be tested with the same statistical sophistication as econometric results. But, as a second best, it is always possible to test the model by means of sensitivity analysis, i.e. changing marginally some parameters so that the stability of the results can be assessed. We do this by changing the depreciation parameter, as this is the only exogenous component in the system.

We apply this linear programming model to estimate both optimal base year and productivity parameters for total investment and infrastructure investment. For infrastructure investment, we call the parameters $c$ and e, instead of $a$ and $b$, to avoid confusion. We use a data set from Mexico for the period 1950 to 1985 . Notice that for this method to work, the series should be long enough to go across cycles, i.e. so as to include both peaks and troughs. The debt crisis that started at the end of 1982 makes 
less useful to extend the data beyond that point, as output fell significantly on account of the drying up of foreign capital inflows. This represents a foreign-exchangeconstrained growth. This in turn may have significantly affected public investment later (Bacha, 1991). But here the output constraint was not originated by infrastructure investment itself, but as a result of foreign exchange shortages. We are however trying to assess the impact of infrastructure shortages (surplus) when other variables are not strongly influencing this result. Proceeding otherwise would produce valid results anyway, but the analysis of its causes has to be brought to the fore.

Lastly, as a measure of output and total investment we use gross domestic product (GDP) and gross fixed capital formation (GFCF), respectively. And as a measure of "core infrastructure" we use a series, derived from GFCF, especially built up for the $\operatorname{purpose}^{(6)}$.

\section{The Results}

\subsection{Two-Gap Model against Time}

Assuming depreciation rates of 7 percent for GFCF and 4 percent for Infrastructure Investment ${ }^{(7)}$, the linear programme produces the following estimated values for the model: $\mathrm{Y} *_{0}=124779, \mathrm{a}=0.97, \mathrm{~b}=0 ; \mathrm{c}=1.78$ and $\mathrm{e}=0.14$. Where $\mathrm{a}$ and $\mathrm{b}$ belong to the calculation using GFCF, and c and e to that using Infrastructure Investment. While the programme does not pick a linear marginal productivity change (b) for GFCF over the period, it does do so for Infrastructure Investment (e). Tables 1 and 2 below show 


\begin{tabular}{|c|c|c|c|c|c|c|c|c|c|}
\hline & [1] & [2] & [3] & [4] & [5] & [6] & [7] & [8] & [9] \\
\hline & $\overline{x x x}$ & $\overline{x x x}$ & $\overline{x x x}$ & [2] - [1] & [3] - [1] & [2] - [3] & $Y^{*} s$ or $Y^{*} f$ & {$[7]-[1]$} & {$[8] /[7]$} \\
\hline & $\bar{Y}$ & $\overline{Y^{*} S}$ & $\overline{Y * f}$ & $Y^{*} \mathbf{S}-\mathrm{Y}$ & $Y^{*} f-Y$ & $Y^{\star} S-Y^{\star} f$ & $\overline{Y^{*}}$ & $Y^{*}-Y$ & $\%$ \\
\hline & $\begin{array}{l}\text { Actual } \\
\text { Output }\end{array}$ & $\begin{array}{c}\text { Optimal } \\
\text { Output }\end{array}$ & $\begin{array}{l}\text { Optimal } \\
\text { Output }\end{array}$ & $\begin{array}{c}\text { Actual } \\
\text { Gap }\end{array}$ & $\begin{array}{c}\text { Actual } \\
\text { Gap }\end{array}$ & $\begin{array}{c}\text { Optimal } \\
\text { Two-Gap }\end{array}$ & $\begin{array}{l}\text { Feasible } \\
\text { Optimum }\end{array}$ & $\begin{array}{c}\text { Feasible } \\
\text { Gap }\end{array}$ & $\begin{array}{c}\text { Feasible } \\
\text { Gap }\end{array}$ \\
\hline 1950 & 124779 & 124779 & 124779 & 0 & 0 & 0 & 124779 & 0 & 0 \\
\hline 1951 & 134429 & 134429 & 139336 & 0 & 4907 & -4907 & 139336 & 4907 & 4 \\
\hline 1952 & 139775 & 148331 & 151743 & 8080 & 11968 & -3412 & 151743 & 11968 & 8 \\
\hline 1953 & 140158 & 162117 & 162022 & 21193 & 21864 & 96 & 162022 & 21864 & 13 \\
\hline 1954 & 154168 & 174069 & 172151 & 19252 & 17983 & 1917 & 173420 & 19252 & 11 \\
\hline 1955 & 167270 & 186067 & 183329 & 18380 & 16059 & 2738 & 185650 & 18380 & 10 \\
\hline 1956 & 178706 & 200320 & 192721 & 21236 & 14015 & 7598 & 199942 & 21236 & 11 \\
\hline 1957 & 192243 & 217959 & 200420 & 25066 & 8177 & 17539 & 217309 & 25066 & 12 \\
\hline 1958 & 202467 & 237005 & 209847 & 33623 & 7380 & 27158 & 236090 & 33623 & 14 \\
\hline 1959 & 208523 & 252705 & 220466 & 43669 & 11943 & 32238 & 252192 & 43669 & 17 \\
\hline 1960 & 225448 & 267739 & 231951 & 42416 & 6503 & 35788 & 267864 & 42416 & 16 \\
\hline 1961 & 236562 & 286602 & 244998 & 50409 & 8436 & 41604 & 286971 & 50409 & 18 \\
\hline 1962 & 247615 & 304499 & 263922 & 57814 & 16307 & 40577 & 305429 & 57814 & 19 \\
\hline 1963 & 267396 & 321995 & 280939 & 56304 & 13543 & 41055 & 323700 & 56304 & 17 \\
\hline 1964 & 298662 & 343376 & 298662 & 46812 & 0 & 44714 & 345474 & 46812 & 14 \\
\hline 1965 & 318030 & 372780 & 320783 & 56356 & 2753 & 51997 & 374386 & 56356 & 15 \\
\hline 1966 & 340074 & 402259 & 345677 & 63622 & 5603 & 56581 & 403696 & 63622 & 16 \\
\hline 1967 & 361347 & 435099 & 377266 & 74883 & 15919 & 57833 & 436230 & 74883 & 17 \\
\hline 1968 & 390799 & 472699 & 409369 & 82438 & 18570 & 63330 & 473237 & 82438 & 17 \\
\hline 1969 & 415512 & 514359 & 446101 & 98666 & 30589 & 68258 & 514178 & 98666 & 19 \\
\hline 1970 & 444271 & 558252 & 477636 & 113250 & 33365 & 80616 & 557521 & 113250 & 20 \\
\hline 1971 & 462804 & 605544 & 512118 & 141487 & 49314 & 93426 & 604291 & 141487 & 23 \\
\hline 1972 & 502086 & 648047 & 545544 & 145358 & 43458 & 102504 & 647444 & 145358 & 22 \\
\hline 1973 & 544307 & 697963 & 593502 & 153110 & 49195 & 104461 & 697417 & 153110 & 22 \\
\hline 1974 & 577568 & 758305 & 653191 & 179355 & 75623 & 105115 & 756923 & 179355 & 24 \\
\hline 1975 & 609976 & 823191 & 710876 & 211055 & 100900 & 112315 & 821031 & 211055 & 26 \\
\hline 1976 & 635831 & 894467 & 788761 & 255550 & 152930 & 105706 & 891381 & 255550 & 29 \\
\hline 1977 & 657722 & 961330 & 857391 & 300990 & 199669 & 103939 & 958712 & 300990 & 31 \\
\hline 1978 & 711982 & 1014821 & 935065 & 303183 & 223083 & 79756 & 1015165 & 303183 & 30 \\
\hline 1979 & 777163 & 1082894 & 1046591 & 307471 & 269428 & 36303 & 1084634 & 307471 & 28 \\
\hline 1980 & 841855 & 1174370 & 1176080 & 333119 & 334225 & -1709 & 1176080 & 334225 & 28 \\
\hline 1981 & 908765 & 1284431 & 1333937 & 373628 & 425172 & -49506 & 1333937 & 425172 & 32 \\
\hline 1982 & 903834 & 1415100 & 1508140 & 505076 & 604306 & -93040 & 1508140 & 604306 & 40 \\
\hline 1983 & 887647 & 1501439 & 1639078 & 611048 & 751431 & -137639 & 1639078 & 751431 & 46 \\
\hline 1984 & 885928 & 1530034 & 1711767 & 653379 & 825839 & -181733 & 1711767 & 825839 & 48 \\
\hline 1985 & 848259 & 1564006 & 1777509 & 736008 & 929250 & -213503 & 1777509 & 929250 & 52 \\
\hline
\end{tabular}

Note

[1]: Y (Actual Output);

[2]: $Y^{\star} \mathbf{S}$ (Optimal Output from Total Investment);

[3]: $Y^{\star} f$ (Optimal Ouput from Infrastructure Investment);

[4]: $Y^{\star} s-Y$ (Actual Gap From GFCF);

[5]: $Y^{\star} f-Y$ (Actual Gap from Infr. Investment)

[6]: $Y^{*} s-Y^{*} f$ (Optimal Gap or Two Gaps)

[7]: Lower $Y^{\star}$ (Feasible Optimum: Lower of $Y^{\star} s$ and $\left.Y^{\star} f\right)$

[8]: $Y^{*}-Y$ (Feasible Gap, amount)

[9]: $100\left(Y^{\star}-Y\right) / Y^{\star}$ (Feasible Gap, percent)

d: Depreciation 


\begin{tabular}{|c|c|c|c|c|c|c|c|c|c|}
\hline & [1] & [2] & [3] & [4] & [5] & [6] & [7] & [8] & [9] \\
\hline & $x x x$ & $x x x$ & $x x x$ & [2] - [1] & [3]- [1] & [2] - [3] & $Y^{*} s$ or $Y^{*} f$ & [7] - [1] & {$[8] /[7]$} \\
\hline & $\overline{\mathbf{Y}}$ & $\mathbf{Y}^{*} \mathbf{S}$ & $Y^{*} f$ & $Y^{*} s-Y$ & $\bar{Y}{ }^{\star} \mathbf{f}-\mathbf{Y}$ & $Y^{*} s-Y^{*} f$ & $\mathbf{Y}^{\star}$ & $\mathbf{Y}^{*}-\mathbf{Y}$ & $\%$ \\
\hline & $\begin{array}{l}\text { Actual } \\
\text { Output }\end{array}$ & $\begin{array}{c}\text { Optimal } \\
\text { Output }\end{array}$ & $\begin{array}{c}\text { Optimal } \\
\text { Output }\end{array}$ & $\begin{array}{c}\text { Actual } \\
\text { Gap }\end{array}$ & $\begin{array}{c}\text { Actual } \\
\text { Gap }\end{array}$ & $\begin{array}{c}\text { Optimal } \\
\text { Gap }\end{array}$ & $\begin{array}{l}\text { Feasible } \\
\text { Optimum }\end{array}$ & $\begin{array}{c}\text { Feasible } \\
\text { Gap }\end{array}$ & $\begin{array}{c}\text { Feasible } \\
\text { Gap }\end{array}$ \\
\hline 1950 & 100 & 100 & 100 & 0 & 0 & 0 & 100 & 0 & 0 \\
\hline 1951 & 108 & 108 & 112 & 0 & 4 & -4 & 112 & 4 & 4 \\
\hline 1952 & 112 & 119 & 122 & 7 & 10 & -3 & 122 & 10 & 8 \\
\hline 1953 & 112 & 130 & 130 & 18 & 18 & 0 & 130 & 18 & 13 \\
\hline 1954 & 124 & 140 & 138 & 16 & 14 & 2 & 139 & 15 & 11 \\
\hline 1955 & 134 & 149 & 147 & 15 & 13 & 2 & 149 & 15 & 10 \\
\hline 1956 & 143 & 161 & 154 & 17 & 11 & 6 & 160 & 17 & 11 \\
\hline 1957 & 154 & 175 & 161 & 21 & 7 & 14 & 174 & 20 & 12 \\
\hline 1958 & 162 & 190 & 168 & 28 & 6 & 22 & 189 & 27 & 14 \\
\hline 1959 & 167 & 203 & 177 & 35 & 10 & 26 & 202 & 35 & 17 \\
\hline 1960 & 181 & 215 & 186 & 34 & 5 & 29 & 215 & 34 & 16 \\
\hline 1961 & 190 & 230 & 196 & 40 & 7 & 33 & 230 & 40 & 18 \\
\hline 1962 & 198 & 244 & 212 & 46 & 13 & 33 & 245 & 46 & 19 \\
\hline 1963 & 214 & 258 & 225 & 44 & 11 & 33 & 259 & 45 & 17 \\
\hline 1964 & 239 & 275 & 239 & 36 & 0 & 36 & 277 & 38 & 14 \\
\hline 1965 & 255 & 299 & 257 & 44 & 2 & 42 & 300 & 45 & 15 \\
\hline 1966 & 273 & 322 & 277 & 50 & 4 & 45 & 324 & 51 & 16 \\
\hline 1967 & 290 & 349 & 302 & 59 & 13 & 46 & 350 & 60 & 17 \\
\hline 1968 & 313 & 379 & 328 & 66 & 15 & 51 & 379 & 66 & 17 \\
\hline 1969 & 333 & 412 & 358 & 79 & 25 & 55 & 412 & 79 & 19 \\
\hline 1970 & 356 & 447 & 383 & 91 & 27 & 65 & 447 & 91 & 20 \\
\hline 1971 & 371 & 485 & 410 & 114 & 40 & 75 & 484 & 113 & 23 \\
\hline 1972 & 402 & 519 & 437 & 117 & 35 & 82 & 519 & 116 & 22 \\
\hline 1973 & 436 & 559 & 476 & 123 & 39 & 84 & 559 & 123 & 22 \\
\hline 1974 & 463 & 608 & 523 & 145 & 61 & 84 & 607 & 144 & 24 \\
\hline 1975 & 489 & 660 & 570 & 171 & 81 & 90 & 658 & 169 & 26 \\
\hline 1976 & 510 & 717 & 632 & 207 & 123 & 85 & 714 & 205 & 29 \\
\hline 1977 & 527 & 770 & 687 & 243 & 160 & 83 & 768 & 241 & 31 \\
\hline 1978 & 571 & 813 & 749 & 243 & 179 & 64 & 814 & 243 & 30 \\
\hline 1979 & 623 & 868 & 839 & 245 & 216 & 29 & 869 & 246 & 28 \\
\hline 1980 & 675 & 941 & 943 & 266 & 268 & -1 & 943 & 268 & 28 \\
\hline 1981 & 728 & 1029 & 1069 & 301 & 341 & -40 & 1069 & 341 & 32 \\
\hline 1982 & 724 & 1134 & 1209 & 410 & 484 & -75 & 1209 & 484 & 40 \\
\hline 1983 & 711 & 1203 & 1314 & 492 & 602 & -110 & 1314 & 602 & 46 \\
\hline 1984 & 710 & 1226 & 1372 & 516 & 662 & -146 & 1372 & 662 & 48 \\
\hline 1985 & 680 & 1253 & 1425 & 574 & 745 & -171 & 1425 & 745 & 52 \\
\hline
\end{tabular}

Note

[1]: Y (Actual Output);

[2]: Y*s (Optimal Output from Total Investment);

[3]: $Y^{*} f$ (Optimal Ouput from Infrastructure Investment);

[4]: $Y^{\star} s-Y$ (Actual Gap From GFCF);

[5]: $Y^{*} f-Y$ (Actual Gap from Infr. Investment)

[6]: $Y^{*} s-Y^{*} f$ (Optimal Gap or Two Gaps)

[7]: Lower $Y^{\star}$ (Feasible Optimum: Lower of $Y^{\star} s$ and $\left.Y^{\star} f\right)$

[8]: $Y^{\star}-Y$ (Feasible Gap, amount)

[9]: $100\left(Y^{\star}-Y\right) / Y^{*}$ (Feasible Gap, percent)

d: Depreciation 
the same results in absolute quantities and as index numbers, respectively, over time. World Bank World Development Report 1997 (OUP, Oxford, 1997). Each table shows eight different columns. The first one is the actual GDP, while all the others have been generated using the values from the optimisation exercise. Columns 2 shows the optimal GDP coming from GFCF (assuming accommodating infrastructures), column 3 shows the optimal GDP from infrastructures (assuming accommodating GFCF). Column 4 and 5 show the respective gaps between the two optimal GDP valuations and actual GDP.

Column 6 is our main aim: it shows the gap between the two optimal valuations of GDP, i.e. $\mathrm{Y}^{*}{ }_{\mathrm{s}} \mathrm{Y}^{*}$ f. This represents the results for our two-gap model with respect to time. The gap represents the maximum foregone output due to either a shortage of core infrastructure or a shortage of GFCF. The latter implies a shortage of the noninfrastructure component of GFCF. When the optimal gap entry has a negative sign, the binding gap or constraint is GFCF, as there would be surplus of Infrastructure Investment (or a surplus in the share of infrastructure investment in GFCF). And when the optimal gap entry is positive, the binding gap or constraint is Infrastructure Investment, as there would be a shortage of Infrastructure Investment (or a shortage in the share of infrastructure investment in GFCF).

Column 7, in turn, has been built by taking the smaller of the two optimal GDP valuations, i.e. when the optimal gap is negative, the optimal GDP from GFCF is used and vice versa. Given that only the smaller of the two is feasible, as it represents the maximum constrained growth, we call it "feasible output" or feasible GDP. Finally columns 8 and 9 account for the amount and percentage of actual feasible gap, 
respectively. This represents the maximum foregone output at any one time, for reasons other than infrastructure or productive investment shortages, e.g. inflation, balance of payments problems, capital flights, political instability, and the like. ${ }^{(8)}$

Concentrating on the Optimal Gap (column 6), the results tell us that at the very beginning of the period there appears to have been a well-matched combination of infrastructure and productive investment, i.e. the composition of GFCF was about right. From here, there would have been a shortage of infrastructures up until 1964. And from this year onwards, there appears to have been an infrastructure surplus, which becomes more prominent towards the end of the period. This is not surprising as while infrastructure investments increased its share in GFCF (from 1978-1983), GDP started to fall from 1982 onwards, due to the debt crisis (Williamson, 1990). It can also be seen that the foregone optimal output due to shortages of productive investment is significantly larger than that due to shortages of infrastructures.

Graph 1 below represents this story. For scaling convenience we use the index numbers rather than the absolute values, but this is fully equivalent. Here the actual output and the two optimal outputs are depicted against time. The curves show that the optimal output from GFCF, or $\mathrm{Y}_{\mathrm{s}}^{*}$, and the optimal output from infrastructure, or $\mathrm{Y}_{\mathrm{f}}^{*}$, are the same at the beginning, then the former is slightly above the latter up until they cross each other in 1965 . Then $\mathrm{Y}_{\mathrm{f}}$ is on top of $\mathrm{Y}_{\mathrm{s}}$ and the gap rapidly diverges. The difference between the two curves represents optimal foregone GDP. The actual output $\mathrm{Y}$, as expected, is always below the smaller of the two optimal outputs, the difference representing feasible foregone GDP. 


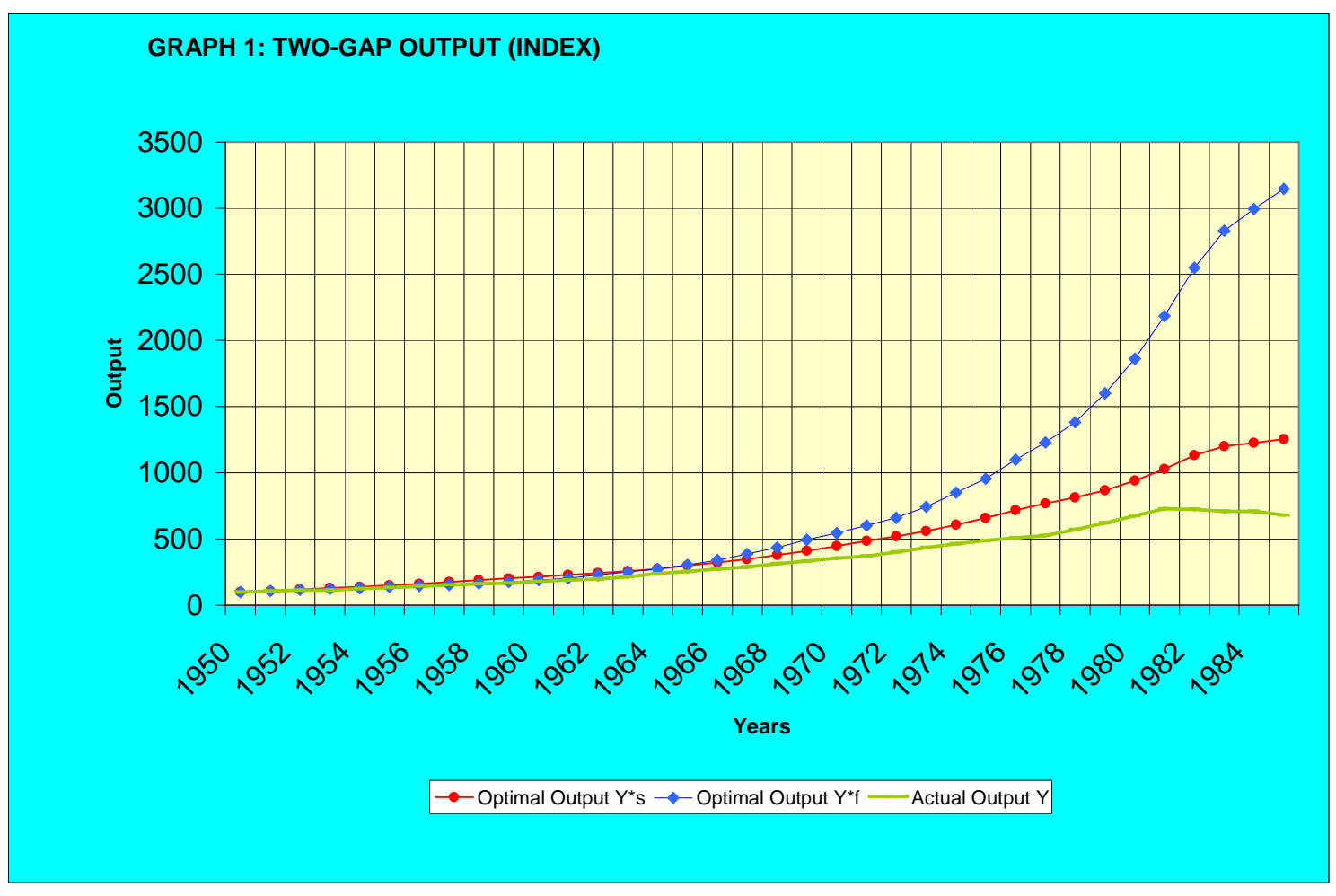




\subsection{Two-Gap Model against Infrastructure Coefficient}

To establish what would be the optimal infrastructure coefficient, $\mathrm{v}_{\mathrm{f}}$, and the optimal capital ratio $\varepsilon$ for the whole period, we have to re-calculate the linear programme, assuming only average productivity parameters for the whole period. That is, we drop the linear marginal parameters $b$ and e from the model. The results from this exercise $\operatorname{are}^{(9)}: \mathrm{Y}^{*}{ }_{0}=124779, \mathrm{a}=0.97$, and $\mathrm{c}=2.37$. That is, only the parameter "c" changes, i.e. the optimal average productivity of Infrastructure Investment.

Equations (9), expressed in terms of $v_{f}$, as $g_{s}=(1 / k) v_{p}+(1 / k) v_{f}$, equation (10), and the value for $\varepsilon$, allow us to have a solution system for growth against infrastructure investment. However, so as to allow for the depreciation $\gamma$, we transform equation (13) into growth rates by, first, dividing both sides by $\mathrm{Y}_{\mathrm{t}-1}$, and then subtracting one from both sides:

$\mathrm{g}^{*}{ }_{\mathrm{t}}=-\gamma+\delta_{\mathrm{t}-1} \mathrm{v}_{\mathrm{t}-1}$

Where $\gamma$ is the depreciation rate (which can vary according to the type of investment), and the coefficient $\delta$ represents either $\alpha=\mathrm{a}$ or $\beta=\mathrm{c}$, whether $\mathrm{v}_{\mathrm{t}-1}$ is the GFCF or the Infrastructure Investment coefficient, respectively. The former would give us the optimal growth rate derived from total GFCF $\left(\mathrm{g}^{*}\right)$, while the latter would give us that derived from infrastructure investment $\left(\mathrm{g}_{\mathrm{f}}\right)$. In turn, the investment coefficients are calculated as $\mathrm{v}_{\mathrm{t}-1}=(\mathrm{GFCF} \text { or Infr. Inv. })_{\mathrm{t}-1} / \mathrm{Y}^{*}{ }_{\mathrm{t}-1}$, i.e. they are calculated with respect to optimal, rather than actual, GDP or output. For GFCF, $\mathrm{v}_{\mathrm{s}}$ can be decomposed into $\mathrm{v}_{\mathrm{p}}$ $+v_{f}$. As we calculated this by taking the whole period as a unit, we can drop the 
subindex "t". For consistency, we then take the value of $v_{p}$, when the optimal gap (in this estimation) equals zero, around $1980\left(v_{p}=9.4\right)$. Therefore, we have two equations and two unknowns: $\mathrm{g}^{*}$ and $\mathrm{v}_{\mathrm{f}}$.

This system solves for growth $g=7.4$ and infrastructure investment $v_{f}=4.5$. So for the period as a whole, at optimal values, there will be a mutual constraint (or wellmatched relationship between investments) when "core infrastructure" investment represents 4.5 percent of optimal GDP. Graph 2 below represents the system in a more customary two-gap graph. It shows that the two curves cross at the system solution points, and that actual growth is on or below the feasible points (lower sections of the two curves $)^{(10)}$. And as expected, it also shows that there would be an infrastructure binding constraint on growth (or infrastructure shortage) any time the infrastructure investment ratio is smaller than 4.5 , and vice versa for values over this point. In turn, to calculate the optimal ratio between capitals, $\varepsilon$, I recall that $\alpha=\mathrm{a}$ and $\beta=\mathrm{c}$. Therefore, using (16), and assuming different depreciation rates, $\gamma_{1}$ and $\gamma_{2}$ (for $\mathrm{g}^{*}{ }_{\mathrm{s}}$ and $\mathrm{g}_{\mathrm{f}}$, respectively), when the two optimal growth equations are equalised, the calculation of $\varepsilon=\left(\mathrm{I}_{\mathrm{p}} / \mathrm{I}_{\mathrm{f}}\right)$ becomes: $\varepsilon=\left[\left(\gamma_{1}-\gamma_{2}\right) / \mathrm{av}_{\mathrm{f}}\right]+(\mathrm{c} / \mathrm{a})-1$.

The result is $\varepsilon=2.1$. That is, for the period as a whole, at optimum, one unit of core infrastructure can sustain slightly over two units of directly productive capital. Or what is equivalent, one unit of infrastructure can support slightly over three units of GFCF. This would constitute a technical/structural optimal relationship for the $\operatorname{period}^{(11)}$. 


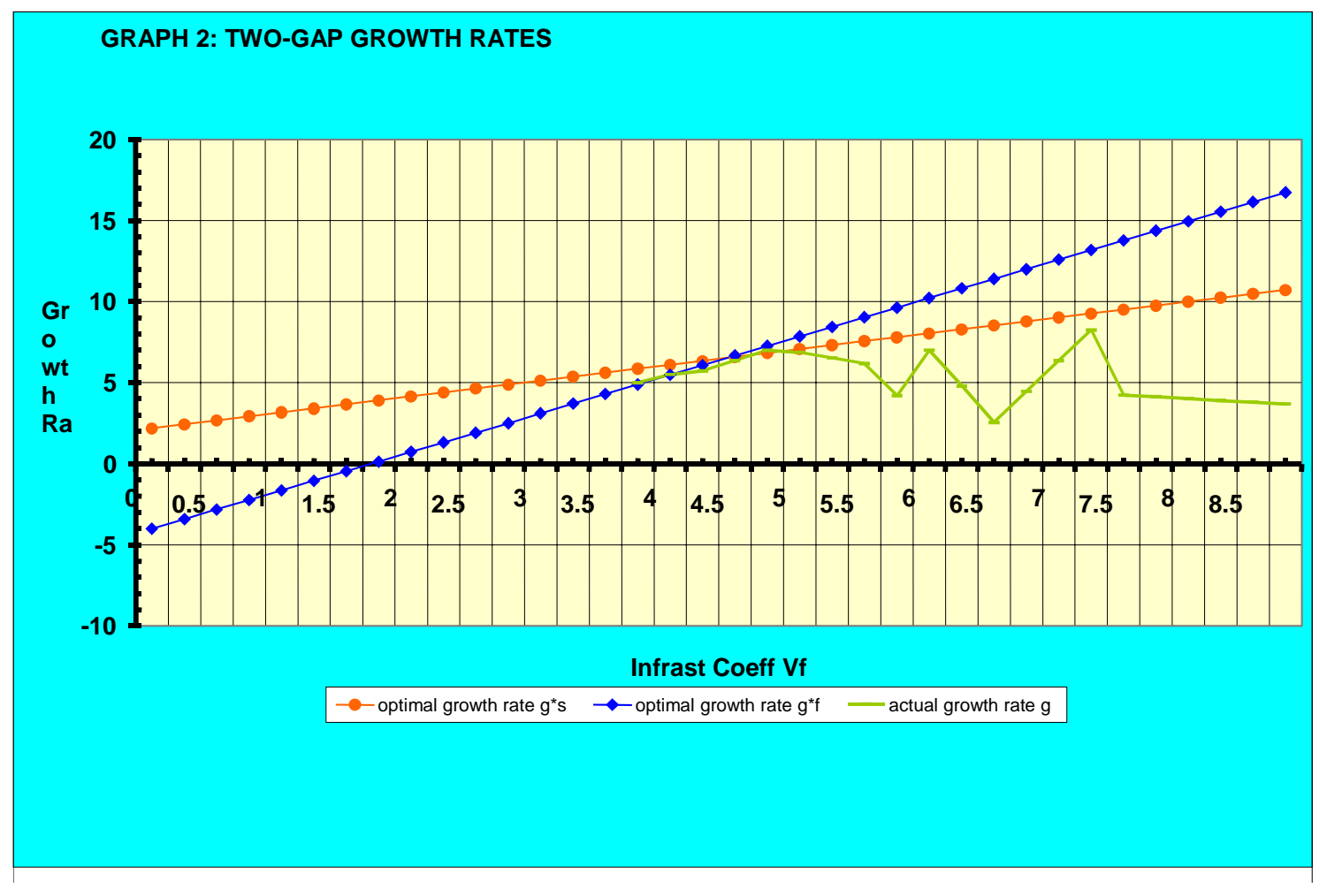




\section{Conclusion}

We have shown that an assessment method derived from a two-gap framework, and applied via linear programming, may tackle the issue of shortage (surplus) of infrastructure at the macroeconomic level with some advantage. The case of Mexico was used as an illustration for our two complementary outlooks, i.e. shortage (surplus) both against time and against infrastructure investment.

The results show that during the sampled period (1950-1985), Mexico appears to have started with an appropriate share of core infrastructures in total gross fixed capital formation $(\mathrm{GFCF})$, i.e. the composition of GFCF was about right. From here, there would have been a shortage of infrastructures up until 1964. And from this year onwards, there appears to have been an infrastructure surplus, which becomes more prominent towards the end of the period, partly on account of the 1982 debt crisis. It also shows that actual output would normally be below the feasible optimal output on account of other standard economic and political determinants.

In turn, the results against infrastructure investment showed that the coefficient of infrastructure investment to optimal output, for the period as a whole, would be around 4.5 per cent. Under this average value, there would have been a shortage of infrastructure, and vice versa, at optimal levels. Not less useful, it appears that each unit of infrastructure could optimally support over three units of GFCF or, what is equivalent, over two units of non-infrastructure or "productive" investment. 
It is true however that if an economy undergoes a macroeconomic shortage (surplus) of infrastructures, that does not necessarily imply that there would be a shortage (surplus) everywhere, but it does imply that the economy as a whole would be in a net state of shortage (surplus). Assuming that our method has a useful contribution at this level, then once this shortage (surplus) has been established, more focussed analysis can be resorted to discriminating between geographic locations, economic sectors, and infrastructure components. So our method may at least provide an appropriate context within which other analysis may be attempted. 


\section{NOTES}

(1) The easy credit to developing countries from 1973 until early 1980s virtually eradicated this model from the economic literature, but it came back with renewed strength after the 1982 Mexico moratorium that heralded the world debt crisis. Given that there was now a serious fiscal constraint, as governments were forced to serve the debt, the model was extended to deal with the so-called "fiscal gap", i.e. a third valuation for ex-ante output or growth. Since then the model is resorted to from time to time in academic literature to analyse constrained growth (Bacha, 1984 and 1990, Eyzaguirre, 1989; Fanelli and Frankel 1989, Taylor, 1991; and others). But, as an accounting model to inform decision making on foreign loans, the World Bank has always used it for its growth programming exercises of member countries, whether in its original form or a modified version of it (Michalopoulos, 1987; Khan et al, 1990).

(2) For example, the so-called "natural" rate of unemployment may be a structural phenomenon, as it keeps changing overtime (as the institutional structure changes), just as with the difference between potential and actual output, accounted by idle capacity (Ormerod, 1995). These could be called "employment gap" and "capacity gap", respectively, allowing a more clearly empirical understanding of them.

(3) It should be pointed out that the standard, ex-ante, demand-determined model can still be entertained for policy analysis. In this case, all that is required is (i) to focus on the generation of savings, especially those for infrastructure purposes, and (ii) to take the potential level of savings as the maximum achievable investment. 
(4) Berg (1984) used it to estimate potential or capacity output in various manufacturing sectors. The method may overestimate capacity in some heterogeneous sectors, but the results appear to be strongly correlated with actual plant information. In turn, Marfan and Artiagoitia (1989) used it for macroeconomic analysis and it appeared to have a fairly good analytical and predicting value.

(5) Notice that this "productivity" represents the ratio of total output (or addition to output) to total capital (or investment). That is, we attribute total output to total capital, but total output is the result of many other factors contributing to it. This then assumes that capital is the pivotal contributor, while all other factors adapt to its requirements, just as the calculation of average productivity of labour via the outputlabour coefficient. Therefore, the coefficient is not actually the productive capacity of capital alone, but an assumedly stable ratio, i.e. this productivity is bound to be a lot larger than the marginal productivity of capital alone. As with the capital-output ratio, it can be corrected, by making explicit all factor contributions (see Thirwall 1994).

(6) The "core infrastructure" series was kindly supplied by Ernesto Piedras, who is writing a $\mathrm{PhD}$ thesis on the subject at the LSE. The other series come from INEGI (1990, 1994), and all of them are calculated in constant 1970 million pesos. In turn, as a simplifying assumption, we use Non-Infrastructure Investment as a measure of "Productive Investment". This allows us to assess the share of Infrastructure Investment in total GFCF.

(7) Depreciation rates of 7 and 4 per cent, respectively, appear as acceptable values. To test the sensitivity of the linear programming model, we actually tried some 
combinations with zero, three, five, and seven percent. The pattern was similar: no gap at the beginning, infrastructure shortage for part of the period afterwards, and infrastructure surplus thereafter, increasing strongly towards the end of the series. In most cases the crossing year was around 1965. The size of the gap may however increase in some calculations, but the overall pattern remains.

(8) Assuming that the feasible output is an accurate quantification of (constrained) potential GDP, then the actually foregone GDP should be smaller than the simple difference between this and the actual output, as economies normally operate with a level of unemployment and idle capacity due to diverse structural causes (Taylor 1991).

(9) For this case, the tables against years are not included, as they are not relevant, but can be requested from the author if required.

(10) The actual values have been calculated by averaging the actual growth rates for similar infrastructure coefficients. In turn, the graph was drawn by joining the calculated points with straight lines.

(11) Under certain assumptions, however, it can also be used as a behavioural relationship to analyse both investment inducement and crowding-in effects, i.e. public investment (in core infrastructure) encourages private productive investment (Bacha 1990, Taylor 1991). 


\section{BIBLIOGRAPHY}

Aschauer, D.A. "Public Capital, Productivity and Economic Growth" in Jonkoping Working Paper, Sweden, 1993.

Aaron, H. "Why is Infrastructure Important? Discussion” in Munnell (1990).

Aschauer, D.A. "Is Public Investment Productive" in Journal of Monetary Economics $(23,177-200,1989)$.

Aschauer, D.A. "Does Public Capital Crowd Out Private Capital?" in Federal Reserve Bank of Chicago, Memorandum 88-10, 1988).

Bacha, E.“A Three-Gap Model of Foreign Transfers and the GDP Growth Rate of Developing Countries" in Journal of Development Economics (32, 279-296, 1990).

Bacha, E. "Growth with Limited Supplies of Foreign Exchange: A Reappraisal of the Two-Gap Model”, in Syrquin (1984).

Barro, R. "A Cross-Country Study of Growth, Savings, and Government", in NBER Working Papers (No. 2855, 1989).

Berg, S.A. "Estimation of Production Capacities in Putty-Clay Production Model: Norwegian Manufacturing Industries, 1962-81", in Scandinavian Journal of Economics (Vol. 3, No. 86, 1984).

Bernt, E, and Hanson, B. "Measuring the Contribution of Public Infrastructure Capital in Sweden" in NBER Working Paper (No. 3842, 1991).

Blejer, M. and Khan, M. "Government Policy and Private Investment in Developing Countries" in IMF Staff Papers (31, No.2, 379-403, 1984).

Chenery, H. "The Application of Investment Criteria" in Quarterly Journal of Economics (No. 57, 1953).

Chenery, H. and Strout, A. "Foreign Assistance and Economic Development", in American Economic Review (No. 56, 1966).

Chenery, H. and Bruno, M. "Development Alternatives in an Open Economy: The Case of Israel", in Economic Journal (Vol. 57, No. 79, 1962).

Chiang, A. Fundamental Methods of Mathematical Economics (McGraw Hill, 3rd Edition, 1984).

Combo, V., et al., (Eds.) Growth-Oriented Adjustment Programs (IMF, Was. D.C., 1897).

Dervis, K., et al., General Equilibrium Models for Development Policy (CUP, Cambridge, 1982). 
Domoto, K. "Infrastructure Investment: Its Impact on Economic Development of Japan during 1885-1940" in International Development Center of Japan, Working Paper Series (No.46, 1992).

ECLA Statistical Yearbook for Latin America (UN, N.Y., Yearly).

Evans, P. and Karras, G. "Is Government Capital Productive? Evidence from a Panel of Seven Countries", in Journal of Macroeconomics (No.3, 1993).

Federal Highway Administration. The Status of the Nation's Highways, Bridges and Transit: Conditions and Performance (FHA, Was. D.C., 1993).

Feltenstein, A. and Ha, J. "The Role of Infrastructure in Mexican Economic Reform", in The World Bank Economic Review (Vol. 9, No. 2, 1995).

Gramlich, E.M. "Infrastructure Investment: A Review Essay" in Journal of Economic Literature (Vol.XXXII, 1176-1196, 1994).

Hirschman, A.O. The Strategy of Economic Development (Yale University Press, New Haven, 1958).

INEGI. Estadisticas Historicas de Mexico (INEGI, Mexico City, 1990, 1994).

Khan, M.S., Montiel, P. and Haque, N.U. "Adjustment with Growth", in Journal of Economic Development (No. 32, 1990).

Mamatzakis, E. "The Role of the Public Sector Infrastructure on Private Sector Productivity in the Long Run Perspectives" in Applied Economic Letters (Forthcoming).

Marfan, M. and Artiagoitia, P. "Estimacion del PGB Potencial: 1960-1988", in Coleccion Estudios Cieplan (No. 27, Santiago, Chile, 1989).

McKinnon, R. "Foreign Exchange Constraints in Economic Development and Efficient Aid Allocation", in Economic Journal (No. 74, 1964).

Michalopoulos, C. "World Bank Programs for Adjustment and Growth", in Combo (1987).

Munnell, A. "Infrastructure and Economic Growth" in Economic Perspectives (Vol. 6, No. 4, 1992).

Munnell, A. (Ed.) Is There a Shortfall in Public Capital Investment (Conference Series No 34, Federal Reserve Bank of Boston, Boston, 1990).

Nurkse, P. "International Investment Today in the Light of Nineteen Century Experience", in Economic Journal (No. 64, 1954). 
Ohkawa, K. and Kohama, H. Lectures on Developing Economies (University of Tokio Press, Tokio, 1989).

Ono, N. Infrastructure Investment in Economic Development: An Empirical Study of Japan and its Comparison with India in International Development Center of Japan, Working Paper (No.39, 1987).

Ormerod, P. The Death of Economics (Faber \& Faber, London, 1994).

Ortiz, G. and Noriega, C. Investment and Growth in Latin America (IMF, mimeo, 1988).

Peterson, G. "Historical Perspective in Infrastructure: How Did We Get Where We Are?" in American Enterprise Institute, Discussion Paper, (February, 1991).

Syrquin, M., et al., (Eds.), Economic Structure and Performance: Essays in Honor of Hollis Chenery (Academic Press, N.Y., 1984).

Taylor, L. Income Distribution, Inflation, and Growth (MIT Press, Cambridge, Mass., 1991).

Taylor, L. Structuralist Macroeconomics (Basic Books, N.Y., 1983).

Thirwall, A.P. Growth and Development (Macmillan, London, 1994).

Todaro, M.P. Economic Development, Sixth Edition (Longman, London, 1997).

Wickerman, W. (Ed.) Infrastructure and Regional Development (Longman, London, 1991).

Williamson, J. (Ed.) Latin American Adjustment. How Much Has Happened? (Institute for International Economics, Was. D.C., 1990).

World Bank World Development Report 1994 (OUP, Oxford, 1994).

World Bank World Development Report 1997 (OUP, Oxford, 1997). 